\title{
A RESOURCE BASED AND CONTEXT DEPENDENT MODEL OF FIRM COMPETITIVENESS
}

\author{
Öznur Özdemir \& Meltem Denizel \\ Sabanc1 University, Istanbul
}

\begin{abstract}
This study aims to provide a conceptual analysis of the main sources of firm level competitiveness. To accomplish this goal, we develop a resource based and context dependent model of firm competitiveness which accounts for both the resource and the environment aspects of competitiveness. Particularly, our model specifies how and under which conditions firm resources can have competitive advantage generation potential and can give rise to actual competitive advantage, and in what ways contextual factors can be influential in this process. Prior to presenting our model, we outline the two main frameworks of the strategy literature on competitiveness analysis, namely $R B V$ and I-O model. We review the subsequent empirical studies applying them to real life settings and discuss the commentaries highlighting their implicit assumptions and possible limitations. Our model draws upon some of the central tenets of these two frameworks, especially those of the resourcebased analysis; however extends them in a number ways and in a way presents a new interpretation of resource-based approach.
\end{abstract}

\section{INTRODUCTION}

In today's global business environment, competitiveness is very crucial for superior performance in marketplace. In order to survive and be profitable, firms should establish and improve competitive advantage over their competitors. However, competitive advantage is not an easy concept to define and evaluate. Several factors, directly or indirectly, affect and jointly determine the competitive strength of an individual firm. The challenge is the identification of these specific factors, and how and to what extent they influence firm competitiveness. This study addresses these questions through a new model which incorporates both the firm specific (internal firm resources) and the environment based determinants (industry and country-related factors) of competitive advantage and examines how and under which conditions firm resources can lead to competitive advantage and how the industry and the country-related factors can be influential in this process.
Due to the importance of the concept, competitiveness and its key contributors have been widely investigated in the literature. Two major research streams, the Resource Based View (RBV) with its focus on the internal firm attributes and the Industrial Organization Model (I-O) on the industry characteristics, have provided extensive analyses of firm level competitiveness from different perspectives. RBV primarily emphasizes internal firm attributes and explains how they may lead to sustained competitive advantage but it lacks the explicit consideration of the external factors. I-O model, on the other hand, carries out an industry oriented analysis and particularly examines the specific industry conditions that may give rise to competitive advantage. Taking into consideration the conclusions of the subsequent empirical studies that reveal the intertwined nature of resource and environmentbased factors, the next step seems to be developing models that will reflect the interaction of firm resources and the wider business environment in generating competitive advantage. In this study, we aim to present such a model that regards internal firm resources as the fundamental component of firm competitiveness and also explicitly incorporates the effect of the environmental determinants via industry and country-related factors.

In the next section we will make a brief overview of the related literature especially focusing on RBV and Industrial Organization approach.

\section{LITERATURE REVIEW}

The first emergence of strategy and competitiveness studies dates back to the basic SWOT analysis where researchers have placed equal emphasis on the firmbased strengths and weaknesses analysis and the environment-based threats and opportunities analysis. One of the initial studies in this genre is 'The Concept of Corporate Strategy' by Andrews (1971) where he cites formulation and implementation as the two important aspects of corporate strategy and defines corporate strategy as identifying opportunities and threats in the company's environment and claims that before a choice can be made, the company's strengths and weaknesses should be appraised together with resources on hand. Andrews has been accompanied 
and followed by many other researches (Richardson, 1972; Demsetz, 1973; Teece, 1980) and these studies sowed the seeds of competitive advantage research.

In 1980, with the publication of Porter's influential book on generic competitive strategies, the focus has been turned to the environment or more specifically to the industry-based factors. Porter and the subsequent research focused on the industry as the basis of competitiveness and strategy analysis. With Wernelfelt's 1984 article, which is generally regarded as the originator of the more recent RBV studies, the focus once again shifted on the individual firm and its resources. Contemporaneously with Wernerfelt, Rumelt (1984) has published another seminal article in which he discusses some of the core concepts and the central ideas of RBV such as the inappropriateness of 'homogenous and identical firms' assumptions of neoclassical firm theory for the business policy studies, the degree and the importance of intra-industry variance, uncertain imitability and isolating mechanisms like casual ambiguity, specialized assets, unique resources, reputation and image, etc.

In 1991, Barney put forward the main arguments of RBV in a highly compact and formulized manner and after then, this study has been mostly regarded as the fundamental article of resource-based paradigm. It is extended and empirically tested by several successive researchers in many respects.

Another form of analysis in strategy studies has been based on game-theoretic models. In this approach rather than the resources or the industry characteristics, short-term or daily tactical maneuvers that are used to bewilder the competitors are at the center of the analysis (Veliyath and Fitzgerald, 2000).

In the next section, we have a closer look at the two main frameworks, RBV and I-O model, which we utilize in developing our model. We mainly refer to Barney (1991) for RBV and Porter $(1980,1985)$ for industrial organization approach and explain how our model relates to and extends their central arguments.

\section{Fundamental Approaches in Competitiveness Analysis}

Resource-based View: RBV relies primarily on the internal attributes of an organization to describe its position in the competitive environment. It specifies firm resources/capabilities namely, the attributes of a firm's physical, human and organizational capital that enable a firm to conceive of and implement strategies that improve its efficiency and effectiveness (Barney, $1991 ; 102)$, as the main potential determinants of firms' competitive advantage. In RBV, a firm is assumed to have competitive advantage if it is implementing a value creating strategy not simultaneously being implemented by any current or potential competitors (Barney, 1991 p.102). Furthermore, this competitive advantage is assumed to be sustainable when these other firms cannot be able to duplicate the benefits arising from this strategy.

As opposed to the environmental models of competitive advantage, which implicitly assume the homogeneity and the perfect mobility of resources firms operating in a given industry have access to, RBV puts forth two alternative assumptions, namely, resource heterogeneity and immobility. RBV theorists claim that these assumptions, which are also empirically justifiable, are necessary to set the link between firms' internal resources and their performance. Barney (1991) states that even if the degree of heterogeneity of firms' strategic resources in the same industry is an empirical question, some amount of heterogeneity should certainly exist within different firms in order to be able to explain the observed performance differences between firms. Otherwise, all firms possessing identical resources would conceive of and implement the same strategies and could only improve their effectiveness and efficiency to the same extent, ending up with no sustained competitive advantage or performance superiority.

RBV lists four necessary attributes of the firm resources that can generate sustained competitive advantages as;

1) Being valuable (enabling a firm to conceive of and implement strategies that will improve its effec tiveness and efficiency)

2) Being rare

3) Being imperfectly imitable (due to a) unique his torical conditions, b) causal ambiguity between the competitive advantage and the resource giving rise to it, c) social complexity of the resource generat ing competitive advantage)

4) Absence of strategically equivalent substitutes

Undeniably being a very comprehensive and influential perspective, RBV has also received criticisms from strategy researchers. One of the most important of these states that RBV does not meet the requirements of a theory as offered by Rudner (1966) primarily because its statements lack the falsifiability requirement when evaluated in terms of empirical content criterion (Priem and Butler, 2001). Priem and Butler ascertain that fundamental statements of RBV which express the causal link between valuable and 
rare resources and competitive advantage are analytic statements which are essentially true by definition and are not testable. Indeed, the major problem seems to be the circularity existing in the definitions of firm resources, valuable resources, and competitive advantage. To overcome this problem, we adopt a different definition of internal firm resources which leaves out the value concept at this stage, and instead includes the contextual factors that will affect and in fact determine the value of resources. Furthermore, our model employs a performance oriented definition of competitive advantage as opposed to Barney's value creating and rare strategies oriented definition.

Another main criticism for RBV is on its implicit stability and homogeneity assumptions about demand markets. Priem and Butler $(1999 ; 30)$ claim that just as the prior environment-based models simplifies strategic analysis with the implicit assumptions of homogenous and perfectly mobile firm resources, RBV also simplifies strategic analysis with an implicit assumption of homogenous and immobile product markets. They further assert that a synthesis of the resourcebased and environment-based perspectives might be an important next step toward a complete strategy theory just as we attempt to accomplish in this paper.

Industrial Organization Model: This model rooted in the traditional competitive analysis has mainly been advocated by industrial organization economists. Focusing primarily on the external market or industry characteristics and the particular positioning of a firm in its industry to explain its competitive advantage, the advocators of this view (Caves and Porter, 1977, 1978; Porter, 1980; Gilbert, 1989; Tallman, 1991) claim that a sophisticated understanding of the rules of competition determining an industry's attractiveness is needed for shaping competitive strategy. Hence, Porter proposes the five forces model (Porter, 1980) to assess the ability of firms to earn in an industry. He regards industry as the fundamental arena where competition occurs, and argues that competitive strategy should simply be a search for a favorable competitive position in an industry, and should try to establish a profitable and sustainable position against the forces that determine industry competition. Although researchers in this stream emphasize industry conditions as the main determinants of firm competitiveness, the link to the internal firm attributes in creating competitive advantage is implicit in I-O model. However, as opposed to the firm resources origin of RBV, I-O model asserts that firms should initially examine the specific industry structure, accordingly select their competitive strategies (either cost leadership or differentiation) and only afterwards should turn to internal resources and develop or acquire assets required to implement the determined strategies so that they can obtain above-average returns.

RBV and environmental models defines the sustainability of firm competitiveness in different ways. While resource-based researchers emphasize the characteristics of a particular firm resource in ensuring the sustainability of competitive advantage, I-O approach resorts to external factors like entry barriers or isolating mechanisms that will prevent competitors from imitations. Our model will principally adhere to RBV to set the conditions required for sustainable competitive superiority.

The more recent studies of Porter focus on the concept of value-chain which, he proposes as a systematic representation of all the activities a firm performs in order to design, produce, market, deliver and support its product. Porter $(1985 ; 11,26)$ argues that there are mainly two types of competitive advantage a firm can possess: low cost and differentiation which in turn stems from the industry structure and presents the value chain analysis to address the interplay between a firm's activities and the types of competitive advantage. In Porter's analysis each activity is significant to the extent it contributes to the firm's relative cost or differentiation advantage. The value chain approach provides a framework for identifying internal firm activities, which may have the potential to generate competitive advantage for the firm.

\section{Need for a New Model}

The two main frameworks of the strategy literature on the firm competitiveness and competitive advantage have been empirically tested in many different settings (Kotha \& Vadlaman, 1995; Powers \& Hahn, 2003; Spanos, Zaralis, Lioukas, 2004; Chang, 2005; Jacome, Lisboa, Yasin, 2002; Shah, Zeis, Ahmadian, Regassa, 2000; Kim, Nam, Stimpert, 2004; Molina, Pino, Rodriguez, 2004; Makhija, 2003; Coates \& McDermott, 2002; McGahan \& Porter, 1997). All these empirical studies have shown that both frameworks are useful in explaining certain aspects of competitiveness. However; most of them, particularly the more recent ones, (Brush \& Arzt, 1999; Priem \& Butler, 2001; Makhija, 2003) also acknowledge the need for a new model that can incorporate the central arguments of these two views, address their implicit assumptions and shortcomings and thus provide a better understanding of firm competitiveness. Considering this need, in this study we develop $a$ resource based and context dependent model of firm competitiveness. Our model draws upon the basic tenets of the two main approaches but rather than 
merely combining their arguments presents a new analysis that primarily bases on the resource-based paradigm but extends its premises to address environment aspects of firm competitiveness as well. This study particularly aims to identify in what ways and under which conditions firm resources, the fundamental component of firm competitiveness, can lead to competitive advantage and how the contextual factors can affect and determine their competitive advantage generation potential.

In the following sections, we first introduce the key concepts which help us in clarifying our arguments and then propose the formal model.

\section{Definition of Key Concepts}

As RBV establishes, internal firm resources carry primary importance in defining the competitiveness of a firm. Firms can achieve competitive advantage by effective use of their extant resources. Hence, adhering to the main argument of RBV, internal firm resources are regarded as prerequisite for firm competitiveness in our model. However; deviating from the traditional definition, firm resources are defined as all tangible (all kinds of physical assets including machinery \& equipment, plants \& buildings, physical technology, raw materials etc.), intangible assets (knowledge \& information, organizational attributes \& capabilities, firm name \& reputation, patents and copyrights etc.) and human resources. In other words, we do not require the condition of enabling the firm to conceive of and implement strategies that improve its efficiency and effectiveness at this stage and, thus, emancipate the concept of value from the definition of resource. This way, not only we are able to avoid the aforementioned tautology arguments and independently examine the effects of environmental conditions on the value of firm resources, but also we can take into consideration those resources, which may become strategically valuable in the future in an appropriate context, although not perceived as such at present. So, in a way we establish a dynamic model of competitive advantage.

Contextual Factors determining under which circumstances which specific resources can contribute to competitiveness are examined at two major levels, namely as industry-related factors and country-related factors. In other words, we use the term 'context' to include not only the industry of the firm but its wider business environment as well. Having introduced the firm resources and the contextual factors, resources are said to have competitive advantage generation potential when the contextual factors emphasize or favor them in the marketplace. Furthermore, this potential of firm resources are transferred to actual competitive advantage and reflected on objective performance measures if the favored resources are also rare among the competitors of the firm as suggested by Barney (1991). Here, rarity implies being uncommon and seldom possessed by other competitors. Of course, specifying the exact boundaries of rarity is impossible, since it partially depends on the competitive structure of the market and the range of possible utilizations of the resource. For instance, if the industry in question is very large, a resource owned by two or more firms can be still regarded as rare, or alternatively, if the resource can be used or bundled in a number of different ways by its different owners, then again, it can provide competitive advantage to all of its owners. On the other hand, the degree of rarity determines the amount of competitive advantage a resource can provide to the firm. If the firm is the unique owner of the resource or if it can utilize the resource in a very exclusive way, then the amount of competitive advantage the firm can attain will be of highest degree compared to the other cases.

As for the sustainability of competitive advantage, Barney's argument that sustainability requires inimitability and non-substitutability of the contextually favorable and rare resources is preserved; however one more condition, the continuation of the favoring effects of contextual factors, is added. Actually, this condition is also recognized by Barney (1991) under his brief discussion of Schumpeterian Shocks in the industry, but not included in the formal model. Consequently, our model suggests that firms can sustain their competitive advantage, if their competitive advantage generating resources cannot be easily imitated or strategically substituted by their competitors and if, in addition, the context conditions continue to favor and value these resources.

Finally, this study adopts a performance-oriented definition of firm competitiveness. A firm is said to be competitive if it has superior market performance (market share can be used as a proxy here), high profitability (relative profitability of the firm compared to the other firms operating in the same industry or industry average may be used as a proxy) and high market value (especially applicable to firms quoted in exchange markets).

\section{Contextual Factors}

We categorize the contextual factors that determine the competitive advantage generation potential of firm resources at two major levels. The first level is the industry-related factors or characteristics. As stated in the previous sections, these are generally regarded 
as the major determinants of competitive advantage by the advocators of market-based perspective. The second one is the country related factors which, to our knowledge, have not been previously investigated under the topic of firm level competitiveness.

\section{1) Industry-Related Factors}

Arising from the specific characteristics of each industry, these factors set the industrial context and determine what kinds of resources are more important and favorable in a certain industry setting. In other words, they value and emphasize some firm resources over others as potential competitive advantage generators in this particular industry. Therefore, firms possessing these resources and making use of them in their strategies can end up with actual performance increase if, in addition, these resources are also rare among the competitors of the firm. Real-life reflections of this argument can be easily observed. For instance, generally bewildering failure of strong and successful firms in a new industry can be interpreted and explained through this industrial context dependency argument. It is no doubt that a firm successfully and profitably operating in a certain industry possesses some specific valuable resources and these resources provide competitive advantage to the firm in its current industry. However; this does not imply that the same resources can continue to provide the same amount of competitive advantage to the firm in its new industry. It is fairly possible that firm's previously competitive resources may not be able to preserve their competitive advantage generation potential under the new industrial context. Thus, in spite of being very successful in its current industry, the firm may fail in its new industry with its existing resources.

We can classify industry-related factors under the following headings;

$\checkmark$ Entry/Exit Barriers for the Industry: These are the factors that determine the ease of entry to or exit from an industry. A wide range of factors can be cited under this heading. To give some examples from Porter (1980) economies of scale, capital requirements and government policy or regulations specific to this industry can all be considered as entry barriers for a certain industry.

$\checkmark$ Competitive Structure of the Industry: These fac tors specify the competitive conditions in a partic ular industry. A number of criteria like number of firms operating in the industry, relative sizes of the competitors, market share distribution, diversity and characteristics of competitors (Porter, 1980), differentiated vs. undifferentiated target markets can be cited as the determinants of an industry's competitive structure.

$\checkmark$ Supplier Relations of the Industry: The strength and life-span of supplier relations, availability of alternative suppliers and supplier concentration (Porter, 1980) are a few examples of the factors that shape the nature of supplier relations in a cer tain industry and consequently affect the potential of firm resources in generating competitive advan tage.

$\checkmark$ Buyer Relations of the Industry: Ranging from general demographic properties of buyers to buyer concentration and bargaining power, a number of buyer-related factors can alter the value of specific firm resources in an industry.

$\checkmark$ Development Potential of the Industry: Depending on external factors, different industries may be at different points on their growth curves. Some of them may be maturing industries with decreasing rates of growth while the others can be emerging ones with accelerating growth rates. Thus, each industry exhibits different development potential which can considerably alter the value of specific firm resources. To illustrate; in an emerging indus try, firm resources facilitating manufacturing expansions will become valuable because such expansions can increase the market share of firms and add to their competitiveness in growing indus tries.

$\checkmark$ Clustering and Networking: Hill and Brennan (2000) defines a cluster as a geographic concentra tion of competitive firms or establishments in the same industry that either have close buy-sell rela tionships with other industries in the region, use common technologies or share a specialized labor pool. Similarly, Rosenfeld (2000) sees a cluster as a geographically bounded agglomeration of related firms that together are able to achieve synergy. On the other hand, a network is defined as a group of firms with restricted membership and specific, often contractual, business objectives, in which the members choose each other and agree explicitly to co-operate in some way (Brown \& McNaughton, 2002). Both of these special structures provide their members alternative ways to access, acquire, improve and more efficiently utilize their resources and as a result, simultaneously increase their com petitive advantage though it sounds counterintu itive. Thus, belonging to a cluster or a network can considerably affect the value of specific firm resources and firm competitiveness.

$\checkmark$ Product Characteristics: The particular characteris tics of the industry product also carry great impor tance while determining which resources can be more useful for obtaining competitive advantage in a certain industry. 
Although the first four of these seven factors in some way correspond to the determinants in Porter's five forces industry structure model, our model does not strictly abide by Porter's sub-classification scheme. Unlike the five forces model, the aim of this study is not determining the industry profitability but pointing out the industry-related factors that can influence the competitive advantage potential of firm resources, since our model bases on the paradigm that without necessary firm resources, characteristics of industries do not reveal a lot about the competitiveness of individual firms.

The industrial context shaped by the specific occurrences of these factors highlights some specific resources over others and, in a way bestow competitive advantage to the owners of these resources if additionally rarity condition is satisfied. For instance, in an industry where speed, flexibility, customer-orientation and quality are appreciated due to buyer and product characteristics, resources like improved distribution channels, flexible manufacturing and advanced quality control systems carry greater importance and provide competitive edge for their possessors. On the other hand, in another one deprived of effective entry/exit barriers, firm resources that can allow the firm to distinguish and protect itself from its competitors' threat like patent rights, marketing capabilities and brand name or reputation have higher potential to generate competitive advantage. Furthermore, in a developing and highly dynamic industry, resources that can ensure healthy and rapid growth of the firm like an appropriate organizational structure, advanced strategic planning capabilities, innovative and progressive employees will become more crucial for remaining competitive.

\section{2) Country-Related Factors}

Besides the industrial context, the country context in which the firm operates is also very influential on the competitive strength of a firm and thus, should be carefully examined in a comprehensive competitiveness analysis. Here, by 'country', we imply not the nation of the firm but the particular country in which the firm continues its activities, so that the analysis does not only apply to a firm's domestic activities but also comprises the activities carried out in foreign markets.

In a certain country, both government policies/regulations and social/environmental conditions can render some resources more valuable than others and significantly alter their competitive advantage generation potential. Similar to the industrial context case, our country context dependency argument has real-life reflections. To illustrate, failure of large multinationals in some country markets in spite of their considerable investments, useful experiences and substantial resources can be explained in terms of the mismatch between their resources and the country context. Likewise, prevalent success of firms in countries where market and macroeconomic conditions resemble those of their own nations can also be interpreted in this framework.

We examine country-related factors constituting the country context under the following headings;

$\checkmark$ Government Policies and Regulations (e.g. incen tive policies, antitrust laws, legal protection of copyrights and patents (in general intellectual property law), economic treaties with other coun tries, taxation policy, and international union mem berships)

$\checkmark$ Infrastructure of the Country (e.g. telecommunica tion channels, transportation system and techno logical availabilities)

$\checkmark$ Macroeconomic Conditions of the Country (e.g. inflation rate, unemployment rate, economic stabil ity and the credibility of the nation in international financial markets)

$\checkmark$ Environmental Advantage of the Country (e.g. geo graphic location, available natural resources and climate conditions)

\section{$\checkmark$ General Demographic and Cultural} Characteristics of the Market (e.g. income level of average house holds, quality consciousness and priority of aver age consumers, age and education distributions of the population, openness to and demand for inno vative and technological products)

To illustrate, how each of these country-related factors can favor certain firm resources over others, we can consider the following examples. For instance, in a country where effective legal protection for copyrights and patents exists, firms can highly benefit from their technological novelties or innovations and consequently outperform their competitors. Hence, R\&D capabilities become very valuable resources for the firm. Conversely; in a country where such regulations or laws are very weak or insufficient, $R \& D$ resources will not mean a lot for firm competitiveness. As another example, in a poor economy with deteriorating macroeconomic indicators and low national credibility in international financial markets, firms' special connections or capabilities that can allow them to access low-priced financing channels will surely have competitive advantage generation potential. Yet, as a further example, in a country with a particular type of abundant mine reserves that can be utilized in energy 
production, a distinctive technology that can process and convert this source to consumable energy for manufacturing will be a valuable resource and will potentially provide competitive edge to its owner(s).

\section{Model}

Although its central arguments are already revealed in the previous discussions, we can now present the formal model relying on our key concepts. Firm resources, which are considered as prerequisite for competitiveness, gain competitive advantage generation potential depending on the context conditions prevailing in the business environment of a firm. That is to say, current industry and country-related factors favor certain kinds of firm resources over others and designate them as more valuable and important in attaining competitive advantage. These potentially competitive advantage generating resources lead to actual competitive advantage and contribute to the firm's competitiveness if they are also rare among the competitors of the firm. Therefore, our model asserts that firms possessing contextually favorable and rare resources and implementing strategies using these resources can become competitive in the marketplace or, in terms of our competitiveness definition, can achieve superior market performance, higher profitability and higher market value relative to their competitors (Exhibit-I). Furthermore, firms can preserve and sustain their competitive position, if their competitive resources cannot be imitated or substituted with strategically equivalent resources by their competitors (Barney, 1991) and, in addition, if the contextual factors continue to favor these resources. Consequently, considering firm resources as the fundamental piece of the analysis and leaving them aside, five essential requirements for sustainable firm competitiveness can be summarized as follows;

$\checkmark$ Appropriate industrial and country context high lighting the resources held by the firm

$\checkmark$ Rarity of these firm resources

$\checkmark$ Inimitability of these firm resources

$\checkmark$ Non-substitutability of these firm resources

$\checkmark$ Continuation of the favoring effects of the contex tual factors

As a direct consequence of the last requirement, our model implies that current competitive resources may lose their competitive advantage generation potential and leave their place to new ones, if the contextual factors that favor and render them valuable change due to external events. Consequently, competitive strength of firms primarily arising from their contextually valuable resources may increase or decrease as the industry and the country conditions alter over time.
Hence, our model can also be regarded as a dynamic model of firm competitiveness since it can comprehensively explain possible alterations in firm competitiveness.

\section{Conclusion and Possible Extensions}

In this study, we present a resource-based and contextdependent model of firm competitiveness. Although originating from the fundamental arguments of the two main approaches (I-O model and RBV) and mostly committing to RBV to explain the basis of firm competitiveness, our model extends their basic premises in a number of ways and tries to address their implicit assumptions. Addressing both the environment and resource based aspects of competitive advantage in the same model; it provides a more comprehensive and explanatory competitiveness analysis.

Moreover, selecting appropriate proxies for the aforementioned concepts and customizing the contextual factors according to the specific conditions of relevant industries or countries, it can be applied or empirically tested in several real life settings. Indeed, as a next step we plan to conduct such empirical studies in specific industries. Although our analysis provides a wider framework, we believe that it will be more effective and tractable to conduct empirical studies on a functional unit level and examine only a certain group of firm resources each time (e.g. resources associated with production and operations). This way, contextual factors that should be investigated for their effects on firm resources can be much more restricted and the complexity of the analysis can be reduced. Hence, besides its theoretical contribution, our model can also provide useful insights for practitioners who need to assess their potential competitive advantage in different industries or markets and shape their future strategies accordingly. 


\section{FXIHIBIT-1}

\section{Firm Resources}

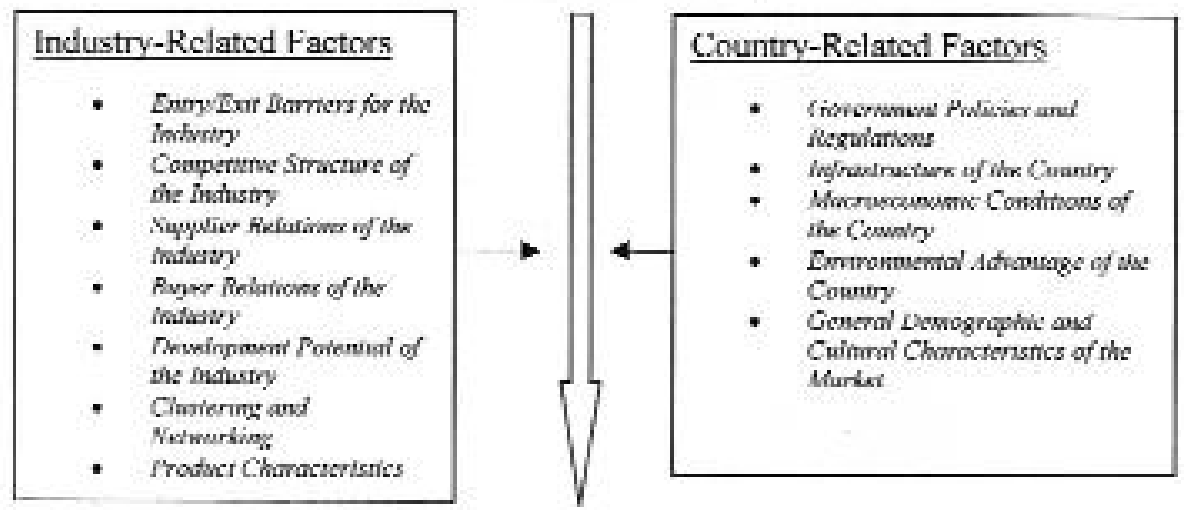

\section{Resources with Competitive Advantage Generation Potential}

Rarity of resurites

\section{Competitive Ressurocs}

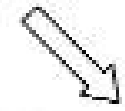

Competitive Advantage

(result in superinr market

perfonnmox, high politabilily, high market share)
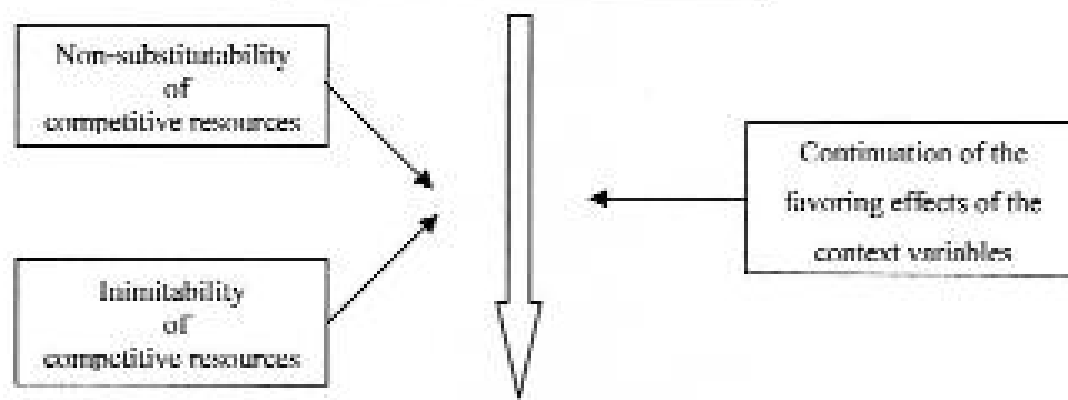

Sustainable Competitive $\Lambda$ dvanlage 


\section{REFERENCES}

Andrews, K. R. , (1971), The concept of corporate strategy. Homewood, IL, Dow Jones Irwin.

Barney, J. B. (1986a), Strategic factor markets: Expectations, luck, and business strategy.

Management Science, 42, pp.1231-1241.

Barney, J. B. (1986c), Types of competition and the theory of strategy: Towards an integrative framework, Academy of Management Review,1, pp.791800 .

Barney, J. B. (1991), Firm resources and sustained competitive advantage, Journal of Management, 17, pp. 99-120.

Barney, J. B. (2001), Is resource-based view a useful perspective for strategic management research? Yes, Academy of Management Review, 26, pp. 41-56.

Sharma, B and Fisher, T. (1997), Functional strategies and competitiveness: an empirical analysis using data from Australian manufacturing, Benchmarking for Quality Management \& Technology, 4, pp. 286-295.

Brush, T. H. and Artz, K. W. (1999), Towards a contingent resource-based theory: The impact of information asymmetry on the value of capabilities in veterinary medicine, Strategic Management Journal, 20, pp. 223-250.

Chang, S.C. (2005), The TFT-LCD industry in Taiwan: competitive advantages and future developments, Technology in Society, 27, pp. 199-215.

Coates, T. T. and McDermott C. M. (2002), An exploratory analysis of new competencies: a resource based view perspective, Journal of Operations Management, 20, pp. 435-450.

Foss, N. J. (1997), A reader in the resource-based perspective. Oxford University Press.

Green, R. F., Lisboa, J. and Yasin, M. 1993. Porter's (1980) generic strategies in Portugal, European Business Review, 93, pp. 3-10.

Hill, E. W. and Brennan J. F. (2000), A methodology for identifying the drivers of industrial clusters: The foundation of regional competitive advantage, Economic Development Quarterly, 14, pp. 65-96.

Hoopes, D. G., Madsen, T. L. and Walker, G. (2003), Guest editors' introduction to the special issue: Why is there a resource-based view? Toward a theory of competitive heterogeneity, Strategic Management Journal, 24, pp. 889-913.

Jacome, R., Lisboa, J. and Yasin, M. (2002), Timebased differentiation - an old strategic hat or an effective strategic choice: an empirical investigation, European Business Review, 14, pp. 184-193.

Kim E.; Nam D. and Stimpert J. L. (2004), Testing the applicability of Porter's generic strategies in the digital age: A study of Korean Cyber Malls, Journal of Business Strategies, 21, pp. 19-45.

Kotha, S. and Vadlamani, B. L. (1995), Research notes and communications assessing generic strategies: An empirical investigation of two competing typologies in discrete manufacturing industries, Strategic Management Journal, 16, pp. 75-83.

Makhija, M. (2003), Comparing the resource-based and market-based views of the firm: Empirical evidence from Czech Privatization, Strategic Management Journal, 24, pp. 433-451.

McGahan, A. M. and Porter, M. E. (1997), How much does industry matter, really?, Strategic Management Journal, 18, pp. 15-31.

Meredith, J. R., McCutcheon, D. M. and Hartley, J. (1994), Enhancing competitiveness through the new market value equation, Operations \& Production Management, 14.

Molina, M. A., del Pino I.B. and Rodríguez, A. C. (2004), Industry, management capabilities and firms' competitiveness: An empirical contribution, Managerial and Decision Economics, 25, pp. 265-281.

Peteraf, M. A. (1993), The cornerstones of competitive advantage: A resource-based view, Strategic Management Journal, 14, pp. 179-188.

Porter, M., (1980), Competitive strategy. New York, Free Press.

Porter, M., (1985), Competitive advantage. New York, Free Press.

Powers, T. L. and Hahn, W. (2004), Critical competitive methods, generic strategies and firm performance, The International Journal of Bank Marketing, 22, pp. 43-64.

Priem, R. L. and Butler, J. E. (2001), Is resource- 
based view a useful perspective for strategic management research?, Academy of Management Review, 26, pp. 22-40.

Priem, R. L. and Butler, J. E. (2001), Tautology in the Resource-Based View and the Implications of Externally Determined Resources Value: Further Comments, Academy of Management Review, 26, pp. 57-66.

Rosenfeld, S. A. (2000), Community college/cluster connections: Specialization and competitiveness in the United States and Europe, Economic Development Quarterly, 14, pp. 51-62.

Rumelt, R. P. (1984), Towards a strategic theory of the firm. Competitive Strategic Management, R. Lamb (Ed.), Prentice Hall, Englewood Cliffs, MD, pp. 556-570.

Shah, A., Zeis, C., Ahmadian, A. and Regassa, H. (2000), Strategies of gaining competitive advantage at the generic and the business unit level: A study comparing American, Japanese and German companies operating in the United States, Multinational Business Review, 8, pp. 13-21.

Spanos, E. Y., Zaralis, G., Lioukas, S. (2004), Strategy and industry effects on profitability: Evidence from Greece, Strategic Management Journal, 25, pp. 139-165.

Veliyath, R. and Fitzgerald, E. (2000), Firm capabilities, business strategies, customer preferences, and hypercompetitive arenas: The sustainability of competitive advantages with implications for firm competitiveness, Competitiveness Review, 10, pp. 56-83.

Wernerfelt, B. (1984), A resource-based view of the firm, Strategic Management Journal, 5, pp. 171-180. 